and a large spectrum of track users involved. Finnish Rescue service has a major partnership project that enables a completely new way to co-operate on safety related matters national wide.

Methods Mx Safety will collect and share the information regarding safety issues and is also developing tools to promote safety. Mx Safety does involve track users to recognise risks and encourage them to make improvements towards safer training conditions.

The most visible project at the moment is basic safety sign standardisation for off road tracks.

National Rescue Service co-operation offers a great opportunity to get national wide risk management, rescue and emergency guidelines for all tracks.

Results An overview of MX Safety signs was first introduced at Motorcycle Show 2015 in Helsinki, in cooperation with the MX Safety project, the cooperative network of emergency services (Pelastuslaitosten Kumppanuusverkosto) and the Finnish Motorcycling Federation. The Finnish Motorcycling Federation (SML) motocross commission has confirmed that MX Safety signs will be introduced at all Finnish motocross tracks latest during 2016. By following common guidelines and best practices and deficiencies motorcycling clubs are able to prevent significant amount of accidents. All tracks users must commit to compliance with common rules. Signs has been translated already in English, Latvian and French languages.

Conclusions Each country is welcome to work together to promote safety.

\section{GEOSPATIAL ANALYSIS OF SPORTS AND LEISURE INJURY HOSPITALISATIONS IN VICTORIA, AUSTRALIA}

Himalaya Singh, Lauren V Fortington, Helen Thompson, Rochelle Eime, Caroline Finch Federation University Australia.

\subsection{6/injuryprev-2016-042156.975}

Background Sports injuries are identified as a major public health problem in Australia and around the world. Sports injury prevention strategies and policy development relies on information about when, where, to whom and how sports injuries occur at a population level. The aim of this research is to investigate the geographical distribution of sports and leisure injures and to identify populations who are at greatest risk of injury.

Methods Data on sports and leisure injury hospitalisations were obtained from the Victorian Injury Surveillance Unit for the years 2005-2011, inclusive. Population-standardised sports and leisure injury hospitalisation rates were calculated for each Local Government Area (LGA). The geographical distribution was investigated using Global Moran's I statistics. Gi* statistics were used to identify statistically significant clustering of high and low values of hospitalisation rates, both overall and for specific activity groups.

Results Mapping by LGA showed a spatial variability in the distribution of injury hospitalisation rates. The Global Moran's I value suggested that hospitalisation rates in Victoria by LGA were spatially clustered. The $\mathrm{Gi}^{*}$ statistics showed a statistically significant clustering of high values for overall hospitalisation rates in the south-western region of Victoria. Similarly, clustering of high values for team ball sports and wheeled motor sports were identified in the western and south-east regions of Victoria, respectively.

Conclusions This study demonstrates that geospatial analysis can be used for better understanding of the population at risk of sport and leisure injury. Findings suggest that priority geographical areas for sports injury prevention can differ depending on the type of sporting activity. These findings will provide a strong evidence base for the strategic planning, development and delivery of sports and leisure injury prevention programs.

\section{MULTIPLE INJURIES IN TEAM BALL SPORTS - HOW ARE DATA COLLECTED AND ANALYSED? A SYSTEMATIC REVIEW}

${ }^{1}$ Lauren Fortington, ${ }^{1}$ Caroline Finch, ${ }^{2}$ Inge van den Akker-Scheek, ${ }^{2}$ Henk van der Worp. ${ }^{1}$ Federation University Australia, Australia; ${ }^{2}$ University of Groningen, Netherlands

\subsection{6/injuryprev-2016-042156.976}

Background A major challenge in sports injury research is that many athletes experience multiple injuries, therefore contributing more than once to the injury tally. Capturing this multiple individual contribution in estimates of sports injury incidence is difficult. The aim of this study is to report how $>1$ individual injury is defined and reported in prospective, long term, sports injury epidemiology studies in team ball sports.

Methods The review was performed and reported according to the Preferred Reporting Items for Systematic Reviews and Metaanalyses (PRISMA) Statement with a systematic search in 3 databases to August 2014. Studies were included if all types of injury were reported in team ball sport participants, with data collected prospectively over $>1$ calendar year or two consecutive sporting seasons. Details on injury definitions, with attention to multiple injuries, were independently extracted by two authors.

Results From 6518 studies, 54 met all inclusion criteria. Injuries or injured players tend to be pooled (grouped) over the whole time period and injury incidence reported as an overall total or annual counts/rates. Both options ignore the potential relationship between injuries sustained by the same individual, within or across seasons. Summarised injury data for the whole cohort was presented even though data collection was in individuals that could have facilitated a more detailed exploration of the relationships between subsequent injuries within those individuals.

Conclusions The way data have been reported in previous sports injury epidemiological studies significantly hinders the ability to provide robust evidence about subsequent injuries. Both an underreporting of new injury incidence and overestimation of injury recurrence can occur if there is no reporting of multiple/ subsequent injuries. Ultimately, injury prevention efforts rely on accurate incidence estimates and ongoing developments in this area can only enhance the field.

\section{SPORTS AND EXERCISE SAFETY IN FINLAND LIVE - AN IMPLEMENTATION PROGRAM TO SPORT CLUBS AND SCHOOLS}

J Parkkari, K Pasanen, A-M Jussila, R Oksanen, A Ojala, K Autio, P Kannus. Tampere Research Centre of Sports Medicine, UKK Institute, Finland

\subsection{6/injuryprev-2016-042156.977}

Background Number of sports injuries has increased in Finland during the past decades. Today sports injuries are the most common injury type. Children, youth and especially young men are at high risk.

Objective The purpose of the LiVE program is to increase safety of sports and exercise in a nationwide setting. 